\title{
Letramentos e identidade profissional: reflexões sobre leitura, escrita e subjetividade na universidade
}

\author{
Miriam A. Graciano de Souza Pan'; https://orcid.org/0000-0002-9704-6958
}

Andriele C. de Lima Litenski ${ }^{1}$; https://orcid.org/0000-0002-3790-798X

\begin{abstract}
Resumo
O artigo investiga as dimensões subjetivas e de constituição das identidades profissionais produzidas pelas práticas de letramento acadêmico. Por meio de uma análise discursiva bakhtiniana, foram analisados os enunciados de quatro estudantes do curso Psicologia da Universidade Federal do Paraná, produzidos durante a realização de oficinas de leitura e escrita. Os enunciados dos estudantes remetem ao sentido de choque em sua experiência com a linguagem acadêmica, vivenciado no momento de ingresso na universidade. Os discursos de identidade que configuram as práticas de leitura e escrita operam sob o signo da competência/incompetência acarretando modos de produção subjetiva que remetem à individualização e culpabilização pelas dificuldades com a escrita científica. Por fim, discute-se a metodologia de oficinas a partir dos fundamentos propostos, como um modelo de intervenção possível para a Psicologia no campo da educação superior.
\end{abstract}

Palavras-chave: Subjetividade; letramento; educação superior.

\section{Lettering and profesional identity: reflections on reading, writing and subjectivity in the university}

\begin{abstract}
The article investigates the subjective and constitutive dimensions of the professional identities produced by academic literacy practices. Through a Bakhtin discursive analysis, the statements of four students of the Psychology course of the Universidade Federal do Paraná, produced during the realization of reading and writing workshops, were analyzed. Students' statements refer to the sense of shock in their experience with academic language, experienced at the moment of joining the university. The identity discourses that shape the practices of reading and writing operate under the sign of competence / incompetence leading to modes of subjective production that refer to individualization and blame for the difficulties with scientific writing. Finally, the workshop methodology is discussed based on the proposed foundations, as a possible intervention model for Psychology in the field of higher education.
\end{abstract}

Keywords: Subjectivity; literacy; college education.

\section{Alfabetización e identidad profesional: reflexiones sobre lectura, escritura y subjetividad en la universidad}

\section{Resumen}

En este artículo se investiga las dimensiones subjetivas y de constitución de las identidades profesionales producidas por las prácticas de alfabetización académico. Por intermedio de un análisis discursivo bakhtiniana, se analizaron los enunciados de 4 estudiantes del curso Psicología de la Universidad Federal de Paraná, producidos durante la realización de talleres de lectura y escritura. Los enunciados de los estudiantes remiten al sentido de choque en su experiencia con el lenguaje académica, vivenciado en el momento de ingreso en la universidad. Los discursos de identidad que configuran las prácticas de lectura y escritura operan sobre el signo de la competencia/incompetencia acarreando modos de producción subjetiva que remiten a la individualización y culpabilidad por las dificultades con la escritura científica. Por fin, se discute la metodología de talleres a partir de los fundamentos propuestos, como un modelo de intervención posible para la Psicología en el campo de la educación universitaria.

Palabras clave: Subjetividad; alfabetización; educación universitaria.

1 Universidade Federal do Paraná - Curitiba - Paraná - Brasil; miriamagspan@yahoo.com.br; andrilitenski@gmail.com 


\section{Introdução}

Ler e escrever são atividades compulsórias no cotidiano universitário; por meio de tais atividades dá-se a apropriação das práticas da futura profissão a ser exercida pelo estudante. O registro de todo o conhecimento histórico produzido e divulgado nas diferentes áreas, ou seja, a memória do saber científico de uma dada profissão só é possível por meio da escrita. A apropriação desse legado, contudo, extrapola a compreensão da linguagem enquanto meio transparente de transmissão do saber de uma esfera profissional e requer pensá-la em suas complexas dimensões sociais, políticas, históricas, subjetivas, e em seus efeitos na formação da identidade profissional do estudante.

De acordo com Ferreira (2013), vasta é a literatura que aborda a escrita nos níveis básicos de ensino, porém, no que diz respeito às práticas de letramento no ensino superior, tais estudos são pouco frequentes. No campo da psicologia eles são ainda mais raros. A explicação apontada pelo autor soma-se a outros estudos que remetem ao entendimento de que uma vez aprovado no exame de redação do vestibular, o estudante já domina a escrita de tal modo que não restariam aspectos a serem trabalhados neste âmbito (Zavala, 2010; Marinho, 2010). Tal compreensão resulta de uma forma de conceber a escrita enquanto um código, meio neutro de registro e transferência do conhecimento, cujo domínio depende do desenvolvimento cognitivo individual (Pan, 2006).

Os filósofos da linguagem que compõem o chamado Círculo de Bakhtin problematizam tal concepção de linguagem e asseveram nos fundamentos que consolidam a sua compreensão como prática social. Para eles a linguagem constitui-se pelo princípio da dialogia (Bakhtin \& Voloshinov, 1929/2014; Bakhtin, 1979/2011), uma vez que decorre de relações de sentido (posições axiológicas) que se estabelecem durante o processo de comunicação verbal (Faraco, 2009). É resposta ativa à cadeia infinita de enunciados (historicidade), pois a palavra viva é sempre endereçada a um outro, no infinito diálogo de vozes que operam sempre sob tensão nos diferentes discursos que configuram um grupo ou uma comunidade, configurados como uma arena de vozes sociais (Bakhtin \& Voloshinov, 1929/2014).

Tal concepção contempla a dimensão verbo-axiológica da língua, pois para esses filósofos, todas as esferas da atividade humana estão relacionadas às práticas de linguagem - e aos valores/sentidos que agregam, as quais se organizam a partir de gêneros discursivos, definidos como tipos relativamente estáveis de enunciados que refletem e refratam as condições e finalidades que cada esfera em seu interior elabora, em cada época e cultura (Bakhtin, 1979/2011, p.280).

Pressupõe-se, assim, que cada grupo social atribui à linguagem verbal (oral e escrita) sentidos próprios que estão relacionados aos usos que fazem dela; nesse sentido, Marinho (2010) ressalta que as práticas de leitura e de escrita na universidade possuem características específicas desse contexto de utilização, o qual afeta os processos de identificação desse grupo, bem como as formas de organizarem seus valores e conhecimentos. Assim, ao apropriar-se das formas próprias de comunicação de uma determinada profissão, o universitário constrói sua identidade profissional.

Se os gêneros discursivos são práticas sociais próprias a uma dada esfera discursiva, eles variam de acordo com seu contexto de utilização, e de acordo com sua complexidade (primários e secundários); assim a comunidade científica possui sua forma própria de comunicação, que não se limita a vivência em apenas um gênero discursivo, mas em vários deles (seminários, resenhas, artigos etc.), em suas distintas complexidades e interpenetrações, e em suas infinitas relações dialógicas, relativas às distintas áreas profissionais, aos diferentes cursos e aos diferentes valores que constituem a identidade própria das instituições de ensino. Desse modo, as significações e identidades produzidas em cada área profissional desta esfera social não se relacionam a essências individuais imutáveis, mas são construídas sócio-historicamente, e por isso, elas se modificam face às práticas discursivas de uma determinada comunidade universitária (Almeida \& Pan, 2017).

Ao aprofundar o debate epistemológico sobre o letramento, o linguista Brian Street propõe ações e reflexões sobre diferentes gêneros acadêmicos no contexto da educação superior a partir de uma visão geral das abordagens da escrita conhecida como "letramentos acadêmicos", construídas sob a luz de tradições mais amplas, como os Novos Estudos de Letramento, que compreendem a leitura e a escrita enquanto práticas sociais, que estão sob influência das relações culturais de poder, as quais possuem efeitos sobre as identidades dos grupos e das comunidades que operam sob tais práticas. (Street, 2010). No caso da educação superior, são as identidades profissionais que estão em jogo, ou seja, que profissionais a universidade pretende formar, e como as práticas de leitura e escrita podem determinar as identidades dos profissionais que forma?

No campo da Psicologia, são poucas as pesquisas que têm abordado o tema da leitura e escrita na universidade, os quais concentram-se no estudo das habilidades dos universitários no que diz respeito ao domínio aos aspectos formais da leitura e da escrita como ortografia, concordâncias verbais e nominais, dentre outros fatores que são considerados relacionados às deficiências de compreensão, à falta de hábito de leitura e ao baixo desempenho acadêmico (Oliveira, Santos, \& Primi, 2003; Cabral \& Tavares, 2005; Cunha \& Santos, 2006; Silva \& Witter, 2008; Cantalice \& Oliveira, 2009; Joly, Dias, Almeida, \& Franco, 2011; Oliveira, Santos, Souto, \& Dias, 2014; Santos \& Fernandes 2016).

Ao priorizar a investigação das questões formais da língua, esses estudos têm se voltado à avaliação do desenvolvimento e do domínio das habilidades de leitura e escrita, sugerindo intervenções nessa direção. Tem-se construído, assim, uma tradição de investigação da linguagem em seus aspectos formais, por um lado, e do estudante em seus aspectos cognitivos, por outro. Tais estudos, segundo Pan (2006), não contemplam as dimensões subjetivas, de constituição de identidades e de poder que as práticas de leitura e escrita envolvem, conforme discutido pelos estudos do letramento. 
Tendo em vista a complexidade do processo de apropriação dos gêneros científicos e a abordagem predominante nas habilidades individuais para o domínio da linguagem escrita nos estudos da Psicologia, considera-se relevante pesquisar outras dimensões da leitura e da escrita na universidade, explorando outros enfoques teórico-metodológicos, como os estudos do letramento, que enfatizam as dimensões de poder e de constituição das identidades em formação, situando-as nas instituições formativas e em suas práticas. Nesse modelo, a dimensão ideológica da linguagem é contemplada, conforme os fundamentos bakhtinianos, trazendo um diferencial em relação às reflexões e práticas sobre as dificuldades em lidar com o conhecimento que circula na comunidade acadêmica, prioritariamente por meio da linguagem verbal (oral e escrita), normalmente localizadas no estudante e em seu histórico de escolarização.

Deste modo, constitui o objetivo deste estudo investigar as dimensões subjetivas produzidas pelas práticas de letramento acadêmico por meio de oficinas de leitura e escrita realizadas com universitários, ou seja, interessa-nos dialogar com os sentidos das práticas de leitura e escrita para os universitários.

\section{Método}

Esta pesquisa foi desenvolvida no Centro de Assessoria e Pesquisa em Psicologia e Educação - CEAPPE, da Universidade Federal do Paraná (UFPR), integrando o Projeto "Identidade, Políticas Inclusivas e Universidade Contemporânea: Desafios à Psicologia Brasileira (PermaneSENDO)". Trata-se de uma pesquisa de caráter interventivo, orientada pelos fundamentos bakhtinianos e situada no campo dos estudos do letramento.

\section{Participantes}

Participaram da pesquisa quatro estudantes do curso de Psicologia da Universidade Federal do Paraná, os quais autorizaram a utilização dos dados produzidos nas oficinas por meio da assinatura do Termo de Consentimento Livre e Esclarecido (TCLE) e serão referenciados com os seguintes pseudônimos: Vanda, João, Maria e Ariel. Todos eram procedentes de escolas públicas cujo ingresso na universidade ocorreu mediante os sistemas de cotas sociais. As idades variaram entre 17 e 22 anos. Provenientes de períodos variados do curso, um estudante era do $1^{\circ}$ ano, dois do $2^{\circ} \mathrm{e}$ um do $5^{\circ}$ ano. Dois deles eram do sexo masculino e dois do sexo feminino.

\section{A oficina como meio de produção dos dados: métodos e procedimentos}

As oficinas foram utilizadas como método de pesquisa-intervenção cujo objetivo é promover reflexões acerca das práticas de leitura e escrita na universidade. Os fundamentos teóricos da metodologia foram propostos por Pan (2003) como alternativa às práticas psicológicas em contextos de educação formal que atuam a partir de uma lógica adaptacionista, individualizada e estigmatizante dos problemas escolares (Pan, 2003; Pan \& Pestana, 2010; Pan \& Zugman, 2015). Delineia-se a partir dos conceitos de experiência e sentido, com destaque à relevância das memórias e do resgate de experiências no processo de construção de sentidos das histórias de cada estudante-autor, processo este que os auxilia na reconstituição de sua cultura, seu tempo, sua história, sua identidade; além disso, configura-se como uma possibilidade de o estudante se posicionar por meio da própria palavra, tornar sua voz audível e contribuir na construção de uma voz coletiva. Ao dar voz aos estudantes, propicia-se um espaço de criação verbal a partir da experiência com gêneros discursivos diversos, e a expressão de sentidos e sentimentos vividos nas práticas cotidianas (Pan \& cols., 2013).

O convite aos estudantes foi feito por meio de cartazes espalhados pelo curso de Psicologia da Universidade Federal do Paraná, os quais continham informações referentes aos objetivos da oficina, sendo a participação voluntária. Foram realizados cinco encontros semanais com a duração aproximada de duas horas cada um, ocorridos nos meses de maio e junho de 2015, no Centro de Assessoria e Pesquisa em Psicologia e Educação (CEAPPE) da Universidade Federal do Paraná.

Para cada encontro era feito um planejamento prévio considerando o objetivo geral das oficinas, o qual, dada a flexibilidade prevista pelo método, contemplava a participação ativa e criativa dos estudantes, que refletiam sobre as práticas de leitura e escrita em seu contexto acadêmico e ativamente colaboravam na seleção dos textos escolhidos (em diferentes gêneros) para leitura e discussão.

As principais atividades desenvolvidas nas oficinas foram rodas de conversa, produções textuais e leituras coletivas nas quais eram feitos apontamentos e comentários; os materiais gerados por essas atividades foram quatro crônicas produzidas pelos estudantes, os diários de campo produzidos em cada encontro e a transcrição do áudio dos encontros.

\section{Intertextos e produção de sentidos: a análise dos dados da pesquisa}

A Análise Dialógica do Discurso fundamentou o tratamento dos dados da pesquisa, assentada na filosofia dialógica da linguagem do Círculo de Bakhtin (Bakhtin \& Volochínov, 1929/2014; Faraco, 2009), ou seja, na compreensão da palavra como signo ideológico. Por meio dela, e das múltiplas vozes que ela veicula, é possível apreender os movimentos de transformação de significações, que produzem os cenários de experiências cotidianas de determinada sociedade, num determinado tempo. Assim, debruçamo-nos na dimensão discursiva da linguagem - a das vozes que 
se apresentam no texto de pesquisa -, retratando a arena discursiva que compõe o cotidiano da vida universitária. A seleção dos textos pautou-se na compreensão de que é da posição exotópica, possibilitada pelo encontro do pesquisador com o outro (alteridade dialógica), que ele irá produzir novos sentidos, no encontro com seu texto de pesquisa (Amorim, 2001; Jobim e Souza \& Albuquerque, 2012).

Sendo assim, a análise teceu um diálogo entre os dados produzidos - as crônicas, os registros (diários de campo e transcrições) - e as vozes que os atravessam, situando-os cronotopicamente. Buscou-se retratar as tensões presentes no cotidiano universitário, evidenciando os modos como os estudantes desconstroem e reconstroem os sentidos da/na universidade, ou seja, como respondem (para-o-outro) e se posicionam (para-si) frente as tensões vividas nas práticas de leitura e escrita nas/pelas quais se constituem suas identidades profissionais.

\section{Resultados e Discussão}

\section{Os gêneros científicos: o primeiro estranhamento}

A entrada na universidade é a realização de um sonho para muitos dos estudantes. Uma vez vencida a batalha do exame vestibular, conquistada a duras penas, após "um ano de malditas olheiras... unhas roídas e muita pressão dos pais" (Ariel) o estudante finalmente ingressa no ensino superior.

Todavia, quando recebe este "prêmio", sente-se "perdido nas aulas", podendo "ter dificuldade com os textos", ficar "confuso com a linguagem da academia e com as avaliações que são realizadas" (Vanda).

$\mathrm{Na}$ Universidade são reproduzidos tipos próprios de enunciados dado às suas funções e às condições de sua produção, definidos como gêneros discursivos complexos ou secundários (Bakhtin, 1979/2011). Desde as aulas, onde oralmente exige-se domínio de leitura de textos e sucessivas indagações sobre os textos lidos, até as resenhas, relatórios, provas e outros, todos fundamentados teórica e metodologicamente na leitura e na escrita científica. Essas formas de comunicação operam com regras próprias, e configuram os chamados gêneros acadêmicos (Street, 2010), os quais se apresentam como uma nova cultura para os estudantes, a qual ele desconhece.

A experiência de inserção em tais gêneros incide em tamanho estranhamento, configurando-se como um choque cultural, pois se observa o conflito de significações entre grupos quando o estudante enuncia: "Que mundo é esse? Vou ter que falar desse jeito nas aulas? Fico pensando nos calouros lendo esse texto, os comentários mais complicam do que ajudam" (João).

O espanto do estudante registra/aponta que na prática - de atividade com a linguagem - os gêneros discursivos próprios da ciência são estranhos aos universitários; de acordo com Vanda, a "escrita é muito diferente daquela do ensino médio, na universidade o padrão é outro".

Além do impacto sentido pelos estudantes durante a sua inserção nos gêneros científicos, outro fator apontado pela estudante e endossado pelos demais é que "todos os professores pedem resenhas e fichamentos, mas ninguém explica como se faz", e que para "usar as normas, tem a ABNT que diz o tamanho da letra, mas algumas coisas vão além disso" (Vanda).

Esses depoimentos indicam o pressuposto tido pela comunidade acadêmica de que o estudante recém ingresso já domina o conjunto de regras que envolvem a leitura e escrita na universidade, ou seja, a comunicação própria desta comunidade; tal pressuposição é tida tanto pelo professor: "A professora me dizia: Como assim você tá na faculdade e não sabe fazer isso?" E pela própria estudante, pois "se a pessoa nos perguntou é porque devemos saber, já que está perguntando, né?" (Maria).

Tal indagação opera de modo imperativo em seus efeitos subjetivos: "devemos saber" produz sentidos no plano do existir da estudante e imputa um dever - o dever de saber ler e escrever, de um certo modo, o qual o estudante desconhece.

Os efeitos desse desconhecimento produzem um duplo choque para os estudantes, primeiro com o modo de comunicação próprio da academia - o gênero acadêmico -, segundo, com as expectativas que a comunidade universitária possui em relação ao domínio desse gênero, para o qual o estudante não foi preparado.

\section{Os sentidos da escrita na universidade: a reprodução}

Em relação às peculiaridades das regras de enunciação nessa esfera, todos os estudantes apontaram como dificuldade recorrente na escrita acadêmica, a necessidade constante de realizar referências, seja por meio de paráfrase ou de outros tipos de citação, modos com quais os participantes da pesquisa afirmaram não terem tido experiências de escrita. Nessa direção um estudante afirma:

Eu sei o que tem que fazer, mas tem que fundamentar. Agora eu tenho que pega a parte escrita do cara, para poder falar de alguma coisa, sabe... a referência é uma parte muito difícil... e é muito isso assim, não é o que você fala, mas o que os outros falam. (João)

A prática da citação faz parte de um conjunto de significados, valores e relações - de poder - entre os membros da comunidade científica, cujas configurações enunciativas requerem do estudante certos posicionamentos na construção discursiva de seus textos, de sua identidade. Nessa perspectiva, a dificuldade apontada pelo estudante se relaciona à posição que a sua voz ocupa mediante as vozes de outros autores, o que extrapola a dimensão técnica da escrita científica. Os estudantes se referem ao quanto des- 
conhecem sobre seus posicionamentos no texto, o que se refere ao fenômeno da autoria, tratado em profundidade pelos teóricos do Círculo de Bakhtin a partir da concepção pluridiscursiva da linguagem (Bakhtin \& Voloshinov, 1929/2014; Bakhtin, 1979/2011). Pensada enquanto prática social, a unidade viva da linguagem - o enunciado - requer resposta e posicionamento, sempre.

A dificuldade em se posicionar diante das vozes de outros autores decorre de algumas confusões quanto à compreensão sobre o que constitui a autoria no texto científico, pois para os estudantes, o sentido da escrita nesse gênero discursivo foge à ideia de uma criação própria, uma vez acreditarem que "nada é seu, é tudo de um terceiro, você só está reproduzindo" (Vanda).

Tendo em vista o sentido de que a escrita na universidade é apenas uma reprodução, a escrita nos gêneros acadêmicos não tem sido apropriada pelos universitários enquanto linguagem própria, mas como palavra de outros. Essa forma de utilização da linguagem impede que os estudantes se posicionem nos discursos e se apropriem do conhecimento com autonomia.

Além disso, as relações de poder que operam nas práticas de leitura e escrita nessa esfera de atividade estabelecem lugares possíveis - e inflexíveis - para os que reproduzem (estudantes) e lugares para os supostos autores, pois para a estudante, se quiser "falar o que você pensa, faz um doutorado! Dai você fala o que você quiser! Me bati um monte na minha monografia, pois ninguém vai me dar crédito por isso" (Vanda).

A constatação de Vanda aponta os sentidos de sua experiência quanto às dimensões de identidade e de poder presentes nos gêneros discursivos da universidade, conforme apontado pelos estudiosos do letramento (Street, 2010; Marinho, 2010; Zavala, 2010),pois sua compreensão é de que são destinados lugares para as pessoas com credibilidade por seus ditos, no caso, os seus professores - pessoas com doutorado -, e para a estudante cabe a posição de reprodução e subordinação ao poder daqueles quem tem a legitimidade para enunciar de modo autoral.

Em síntese, os estudantes apontam que a citação é uma forma de reprodução das vozes alheias, processo pelo qual se dá a(re)produção do conhecimento, pois para Ariel a "ciência é uma sequência infinita de apuds e na universidade você nunca cria nada, só repete”. (Ariel).

Desse modo, a concepção dos estudantes sobre o conhecimento científico aponta para uma relação vivida e sentida como distante da linguagem acadêmica, que os desautoriza a agir de modo criativo e autoral diante do conhecimento produzido nessa esfera de atividade.

Nessa direção, Zavala (2010) afirma que as formas de escrita na universidade e suas convenções se configuram como uma espécie de jogo em que é pedido ao escritor que assuma uma outra identidade, diferente da sua identidade cultural de referência. Essa assertiva vai ao encontro do que o estudante descreve acerca da linguagem acadêmica como sendo coisa de outro mundo.

\section{Produtividade: uma relação instrumental}

Os estudantes mencionaram que o "fazer acadêmico tem uma pesada exigência de produção", ou seja, a lógica da produtividade também é um aspecto norteador de sua relação com a leitura e escrita na universidade. Maria afirma que "gostava de ler poesia" antes de entrar na universidade, mas tem sua relação modificada com o prazer da leitura, pois "com o passar do tempo" ela "perdeu a vontade". "Com a falta de tempo, também perdeu a criatividade" (Maria).

Com o intuito de dar conta da enxurrada de tarefas acadêmicas, os estudantes relatam algumas estratégias recorrentes na forma de produção dos textos, que são divididos, cada aluno de um grupo faz uma parte. Nessa situação, uma estudante menciona: "Eu era a rainha dos fransksteins, juntava tudo e tentava dar algum sentido" (Vanda).

A relação pragmática com as práticas de letramento na universidade, somada ao sentimento de não pertencimento aos processos de produção de conhecimento da comunidade científica, parece responder às demandas de avaliação por resultados, por índices de produtividade mediante a capacidade de entrega de inúmeras tarefas. Demandas essas, presentes na configuração da universidade contemporânea que a define como formadora de competências para o mercado de trabalho, em detrimento de possibilitar aos estudantes o pensamento crítico e reflexivo (Chauí, 2003; Borges, 2013).

Além disso, os discursos de produtividade e de eficiência possibilitam que a leitura e a escrita na universidade adquiram uma dimensão técnica, já que essas práticas são reduzidas à técnica da escrita científica ao invés de exercitar sua dimensão criativa, reflexiva e autoral, no sentido de lidar com as vozes do texto, de orientar-se no universo pluridiscursivo da linguagem. A esse respeito Smolka chama a atenção para o ensino da leitura e da escrita somente enquanto técnica que leva a "efeitos de sentido que produzem uma atividade sem consciência: desvinculada da práxis e desprovida de sentido, a escrita se torna um instrumento de dominação e alienação" (Smolka, 2013, p. 38).

Tal reflexão trazida para o contexto universitário possibilita-nos pensar no processo de produção subjetiva que opera de modo eficaz sob a lógica do produtivismo acadêmico. Nesse ponto começam a ser delineados os sentidos da identidade de um universitário competente. Competente para quê? Para responder às exigências internas de entrega de muitos trabalhos, mesmo que sejam sem sentido- os franksteins -, e de resposta às exigências externas, ou seja, aos índices de produtividade estabelecidos nacionalmente para as universidades, e em resposta às exigências do mercado de trabalho, ao qual a universidade direciona os profissionais que forma.

\section{Discursos de identidade: o estudante competente}

No diálogo com os participantes das oficinas, algumas vozes sobre a identidade do estudante universitário se 
fazem ouvir: para eles um bom estudante "tem um currículo lattes extenso, produz muitos artigos científicos e realiza os fichamentos de todas leituras solicitadas pelo professor" (Vanda).

Tais significações se inscrevem semântico-axiologicamente no discurso das competências, configurando o padrão idealizado de universitário - normal -, o qual é expresso pela eficiência dos estudantes no processo produtivo medido pela capacidade de gerar resultados (artigos, resenhas, resumos, relatórios, seminários, e muitos outros). Os discursos sobre as competências dos estudantes corroboram para a configuração de sua identidade, seja no curso de Psicologia da UFPR, seja nos diferentes cursos e profissões para as quais a universidade forma.

Nessa perspectiva, Magnin e Pan (2015) afirmam que o enunciado das competências, na forma que tem sido utilizado nos discursos oficiais de educação para o trabalho, relaciona-se à noção de autonomia e recai principalmente na individualização dos problemas e das dificuldades, bem como na adaptação dos sujeitos às exigências institucionais, cujos efeitos resultam em modos de subjetivação que classificam e discriminam os sujeitos considerados aptos e inaptos, indivíduos de sucesso ou de fracasso, competentes ou incompetentes.

Tais práticas resultam de relações de poder que engendram as classificações, hierarquizações e binarismos, onde uma polarização é sempre privilegiada, pois recebe um valor positivo, e consequentemente, a outra, recebe um valor negativo. Em forma de hierarquização normativa, elege-se uma identidade específica como parâmetro em relação às outras identidades. A identidade normal é tida como "natural", desejável, única. "A força da identidade normal é tal que ela nem sequer é vista como uma identidade, mas simplesmente como a identidade". (Silva, 2007 p. 18).

\section{Individualização das dificuldades: o sofrimento do estudante}

A experiência subjetiva dos estudantes manifesta-se sob pontos de aceitação e recusa dos discursos de identidade que circulam nas práticas discursivas da universidade. $O$ estudante busca responder, mas nem sempre se reconhece nele. Se o modelo ideal é significado positivamente, o que se diferencia incide em uma negatividade, ou seja, carrega o sentido da incompetência: "O professor deu um texto do Foucault já no primeiro semestre, foi traumatizante" ... "Não entendi nada, me senti burro, pensei que talvez fosse disléxico" (João).

Tal enunciado ilustra o processo de diferenciação dessa identidade positivada no sentido individual de incompetência, na individualização das dificuldades de leitura encontradas e até mesmo na sua significação enquanto possível patologia.

Os discursos de identidade assim configurados encerram uma significação neles mesmos, pois tendem a constranger a dialogia intrínseca de todo discurso, já que elegem a identidade ideal - competente, normal - como parâmetro para os modos de ser estudante. Diante dessa lógica, o sucesso e o fracasso dos estudantes são explicados como procedentes do desenvolvimento de habilidades individuais, naturais, explicações que assinalam o sofrimento presente no cotidiano das práticas educativas formais, uma vez que produzem como efeito, a culpabilização dos estudantes pelo seu insucesso (Pan \& Zugman, 2015).

Nesse sentido, os efeitos subjetivos enunciados pelos estudantes apontam para o sofrimento - os sentimentos de medo, vergonha, auto responsabilização e culpabilização produzidos pelas práticas dominantes de leitura e escrita. Como consequência, sentem-se desencorajados a escrever pensando que os outros podem "rir" deles; ou ficam tão focados em escrever de modo perfeito do ponto de vista gramatical e normativo, que se sentem inibidos em seu processo de criação verbal, tornando-se "travados" (Vanda).

\section{Ressignificando a leitura e a escrita: criação e autoria}

Marinho-Araújo (2009), Bisinoto e Marinho-Araújo(2015)afirmam que a atuação do psicólogo no nível superior de educação deve se direcionar à busca de superação das intervenções individualizantes, presentes nas práticas tradicionais da psicologia educacional, combatendo a lógica da padronização e homogeneização das subjetividades. Reafirmam perspectivas críticas na concepção do fenômeno educacional em sua complexidade, já consolidadas na psicologia educacional brasileira, apontando o modelo institucional como forma de enfrentamento às abordagens instantâneas de resolução das queixas.Propõem formas alternativas de trabalho por meio de análise e intervenção coletiva, pressupondo que as questões subjetivas possuem desdobramentos institucionais e discursivos.

A partir do trabalho com as oficinas foi possível desnaturalizar os discursos das competências individuais para o domínio das dimensões formais da língua escrita, desmistificando a frequente autoreferenciação em relação aos problemas e dificuldades com a linguagem acadêmica. Tais dificuldades foram analisadas e refletidas de modo recorrente, como inexperiência para com os gêneros acadêmicos, não se tratando, portanto, de dificuldades relativas às estruturas linguísticas, tampouco de dificuldades cognitivas do estudante em operar com a própria língua. A respeito do espaço criado para a discussão e ressignificação das dificuldades, uma estudante afirma: "É muito bom poder discutir essas questões com outras pessoas porque você acha que é só com você, e daí você percebe que não é só com você mesmo" (Maria).

De acordo com a avaliação dos estudantes, as oficinas tiveram um aspecto positivo em sua relação com as práticas de leitura e escrita tanto nos gêneros acadêmicos como em outros gêneros discursivos, explorados ao longo do trabalho. Nessa direção, os estudantes relatam que passaram a escrever seus textos tendo em vista o endere- 
çamento, bem como, buscando a contextualização histórico-dialógica de suas produções.

Considerando os pressupostos teórico-metodológicos assumidos, as oficinas possibilitaram que os sentidos atribuídos às práticas de leitura e escrita na universidade pudessem ser ressignificados, levando a uma ação mais criativa e autoral sobre a língua, por parte dos estudantes, ou seja, produzindo uma maior consciência sobre o modo de operar dos gêneros científicos, contrastivamente aos outros gêneros trabalhados, com os quais eles se identificavam. Acerca disso, foi possível ouvir dos participantes que as atividades desenvolvidas possibilitaram atribuir novos sentidos para o conhecimento e para a posição discursiva que ocupam enquanto autores, ao participar ativamente no processo de produção de sentidos, durante as atividades de leitura e escrita. Ainda, ouve-se em suas avaliações, a necessária subversão dos sentidos dos discursos hegemônicos de individualização das dificuldades no letramento acadêmico, que recaem na culpabilização individual. A esse respeito um dos estudantes avaliou: "Eu relembrei do quanto gosto de escrever textos em vários gêneros, de criar,sabe"! (Ariel).

\section{Considerações Finais}

O estudo evidenciou que os sentidos atribuídos ao letramento acadêmico apontadas pelos estudantes remetem muito mais do desconhecimento das convenções discursivas da linguagem científica - os gêneros acadêmicos - do que do domínio dos aspectos formais da linguagem verbal.

Além disso, os enunciados dos estudantes indicaram os efeitos dos discursos de identidade operando nas práticas de letramento acadêmico sob o signo da competência/ incompetência, que tem se configurado por modos homogeneizadores e normalizadores de produção da subjetividade, já que as interpretações das dificuldades por eles enfrentadas no cotidiano das práticas pedagógicas produzem como efeito, a auto responsabilização pelo fracasso - na leitura, na escrita e em outras formas de comunicação verbal -, incorrendo na produção de sofrimento.

Diante de tais práticas, as oficinas se mostraram como estratégia possível de atuação profissional, incidindo na desnaturalização das dificuldades dos estudantes significadas como (in)competências individuais, bem como, criaram um espaço para os estudantes se posicionarem diante dos textos que leem, situando-os em suas matrizes discursivas. Também puderam expressar e compartilhar seus sentimentos e sofrimentos diante das excessivas tarefas exigidas, muitas vezes executadas sem sentido, e sem apropriação/ domínio do gênero. $E$ mais, sem que alguém explique como fazer, por exemplo, uma resenha, um relatório, ou mesmo, uma citação, a paráfrase, a condensação.

Por fim, as oficinas apontaram possibilidades para a criação de outros sentidos às práticas do psicólogo na universidade, principalmente porque foram direcionadas aos próprios estudantes do curso de Psicologia, problema- tizando a representação social do profissional que se ocupa normalmente dos desvios da aprendizagem nos contextos de educação formal. Ao trabalhar em uma perspectiva que almeja a redução do sofrimento gerado pelas práticas instrumentais de letramento, e pelas concepções de linguagem que nelas veiculam, as oficinas possibilitaram a criação de um espaço para otimização da aprendizagem e promoção do desenvolvimento dos estudantes.

\section{Referências}

Almeida, A. B.; Pan, M. A. G. S. (2017). Contribuições bakhtinianas para o estudo das práticas de leitura e escrita na universidade: autoria, gêneros científicos e identidade profissional. In: Pan, M. A. G. S.; Albanese, L.; Ferrarini, N. L. (Orgs.), Psicologia e educação superior: formação e $(m)$ prática (pp. 75-98). Curitiba: Juruá.

Amorim, M.(2001). O Pesquisador e seu outro: Bakhtin nas ciências humanas. São Paulo: Musa.

Bakhtin, M. M.; Voloshinov, V. N. (2014). Marxismo e filosofia da linguagem: problemas fundamentais do método sociológico da linguagem (16 ed.). (M. Lahud \& Y. F. Vieira, Trad.). São Paulo: Hucitec. (Trabalho original publicado em 1929).

Bakhtin, M. (2011). Estética da criação verbal (6 $6^{a}$ ed). (P. Bezerra, Trad.). São Paulo: Martins Fontes. (Trabalho original publicado em 1979).

Bisinoto, C.; Marinho-Araujo, C. (2015). Psicologia Escolar na Educação Superior: panorama da atuação no Brasil. Arquivos Brasileiros de Psicologia, 67(2), 33-46. Recuperado: 20 jun.2017. Disponível: $\quad$ http://pepsic.bvsalud.org/scielo.php?script=sci_ arttext\&pid=S1809-52672015000200004\&lng=pt\&tlng=pt.

Borges, M. C. A. (2013). Reforma da universidade no contexto da integração europeia: o processo de Bolonha e seus desdobramentos. Educação \& Sociedade, 34(122), 67-80. Doi: https://dx.doi.org/10.1590/S0101-73302013000100004

Cantalice, L. M.; Oliveira, K. L. (2009). Estratégias de leitura e compreensão textual em universitários. Psicologia Escolar e Educacional, 13(2), 227-234. Doi: https://dx.doi.org/10.1590/ S1413-85572009000200004

Cabral,A. P.; Tavares, J. (2005). Leitura/compreensão, escrita e sucesso acadêmico: um estudo de diagnóstico em quatro universidades portuguesas. Psicologia Escolar e Educacional, 9(2), 203-213. Doi: https://dx.doi.org/10.1590/S1413-85572005000200003

Chauí, M. (2003). A universidade pública sob nova perspectiva. In: Revista Brasileira de Educação, 24, 5-15.

Cunha, N. B.; Santos, A. A. A. (2006). Relação entre a compreensão da leitura e a produção escrita em universitários. Psicologia: Reflexão e Crítica, 19(2), 237-245. Doi: https://dx.doi.org/10.1590/ 
Faraco, C. A. (2009). Linguagem e Diálogo: as ideias linguísticas do círculo de Bakhtin. Curitiba: Criar Edições.

Ferreira, M. L. S. (2013). Letramentos acadêmicos em contexto de expansão do ensino superior no Brasil. Tese de doutorado, Faculdade de educação da UFMG, Belo Horizonte.

Jobim e Souza, S.; Albuquerque, E. D. P. (2012). A pesquisa em ciências humanas: uma leitura bakhtiniana. Bakhtiniana: Revista de Estudos do Discurso, 7(2), 109-122. https://dx.doi.org/10.1590/ S2176-45732012000200008

Joly, M. C. R. A.; Dias, A. S.; Almeida, L. S.; Franco, A. H. R. (2011). Competências de estudo e leitura em universitários. In: Actas do VIII Congresso Iberoamericano de Avaliação Psicológica/ Evaluación Psicológica XV Conferência Internacional Avaliação Psicológica: Formas E Contextos (pp. 85-95). Lisboa: Faculdade de Psicologia e de Ciências da Educação da Universidade de Lisboa. Recuperado: 19 jun. 2017. Disponível: http://www.rcaap. pt/detail.jsp?id=oai:repositorium.sdum.uminho.pt:1822/17243.

Magnin, L.; Pan, M. (2015). As políticas de educação continuada por competências: um estudo das configurações subjetivas do trabalhador público brasileiro. Cadernos de Psicologia Social do Trabalho, 18(2), 153-167. Doi: http://dx.doi.org/10.11606/ issn.1981-0490.v18i2p153-167

Marinho-Araújo, C. M. (2009). Psicologia Escolar na Educação Superior: novos cenários de intervenção e pesquisa. In: C. M. Marinho-Araújo (Org.), Psicologia Escolar: novos cenários e contextos de pesquisa, formação e prática (pp. 155-202). Campinas: Editora Alínea.

Marinho, M. (2010). A escrita nas práticas de letramento acadêmico. Revista Brasileira de Linguística Aplicada, 10(2), 363386.

Oliveira, K. L.; Santos, A. A. A.; Primi, R. (2003). Estudo das relações entre compreensão em leitura e desempenho acadêmico na universidade. Interação em Psicologia, 7(1), 19-25. Doi: http:// dx.doi.org/10.5380/psi.v7i1.3203

Oliveira, C. T., Santos, A. S., Souto, D. C., \& Dias, A. C. G. (2014). Oficinas de elaboração de comunicação e escrita científica com estudantes universitários. Psicologia: Ciência e Profissão, 34(1), 252-263. Doi: https://dx.doi.org/10.1590/S141498932014000100018

Pan, M. A. G. S. (2003). Infância, discurso e subjetividade: uma discussão interdisciplinar para uma nova compreensão dos problemas escolares. Tese de Doutorado, Universidade Federal
Pan, M. A. G. S. (2006). Letramento escolar e processos subjetivos. In: Berberian, A. P.; Massi, G.; Mori-de-Angelis, C. (Orgs.), Letramento: referências em saúde e educação (pp. 66-115). São Paulo: Plexus.

Pan, M. A. G. S.; Pestana, G. M. (2010). Ateliers dÁrts: contributions de la psychologie à l'inclusion scolaire. Les Actes de Lecture, 110, 71-77

Pan, M. A. G. S.; Bevilacqua, C.; Branco, P. I.; Moreira, J.; Litenski, A. C.; Rhodes, C. A.; Tovar, A. A.; Zonta, G. A., (2013). Psicologia Educacional na Universidade: A Construção de Um Modelo Junto à Assistência Estudantil. In: Anais do / Seminário Iberoamericano: as transições dos estudantes, um desafio para as universidades. Itajaí - SC.

Pan, M. A. G. S.; Zugman, M. J. (2015). Psicologia e políticas inclusivas na educação: contribuições de uma leitura bakhtiniana. Estudos e Pesquisas em Psicologia, 15(1), 135-154.

Santos, A. A. A.; Fernandes, E. S. O. (2016). Habilidade de escrita e compreensão de leitura como preditores de desempenho escolar. Psicologia Escolar e Educacional, 20(3), 465-473. Doi: https:// dx.doi.org/10.1590/2175-3539201502031013

Silva, T. T. (2007). A produção social da identidade e da diferença. In:Silva,T. T. (Org.), Identidade e diferença: a perspectiva dos estudos culturais ( $7^{\mathrm{a}}$ ed, pp. 73-102). Petrópolis, RJ: Vozes.

Silva, E. M. T.; Witter, G. P. (2008). Compreensão de texto e desempenho acadêmico em estudantes de psicologia. Estudos de Psicologia, 25(3), 395-403. Recuperado: 19 jun. 2017. Disponível: http://www.scielo.br/pdf/estpsi/v25n3/a08v25n3.pdf

Smolka, A. L. B.(2013). A criança na fase inicial da escrita. Alfabetização como processo discursivo (13 $\left.3^{\mathrm{a}} \mathrm{ed}\right)$. São Paulo: Cortez.

Street, B. (2010). 'Academic Literacies approaches to Genre'? Revista Brasileira de Linguística Aplicada,10(2) 347-361. Disponível: http:// www.redalyc.com/articulo.oa?id=339829613004ER -

Zavala, V. (2010). Quem Está Dizendo Isso? Letramento Acadêmico, Identidade e Poder no Ensino Superior. In: Vóvio, C.; Sisto, L.; Grande, P. B. (Orgs.), Letramentos: Rupturas, Deslocamentos e Repercussões na Pesquisa em Linguística Aplicada (pp. 71-95). Campinas, SP: Mercado de Letras.

Recebido: 19 de julho de 2017 Aceito: 19 de julho de 2018

(cc) EY License information: This is an open-access article distributed under the terms of the License (type CC-BY), which permits unrestricted use, distribution and reproduction in any medium, provided the original article is properly cited. 